\section{SCARLATINA MALIGNA.}

By A. MYERS, Esq.,

Ascistant-Surgeten xst Battalion Coldstream Guards, Tower of London.

Two cases of the above disease, terminating rapidly in death and taking rather an unusual course, having lately come under my observation, 1 think a short report of them may be of interest to the profession.

CASE I. - A hoy, aged 3 years and 3 months, previously healthy, excepting that he had a mild attacks of measles in December, awoke at 1 cepting January 6 th, complained of sickness, and vomited several times until 7 A.M., when he was, slightly convulsed. At II A.M., when first seen by me, he was slightly teverish, wh quick pulse; his skin was rather hot; the tongue coated with a brownish fur on each side of the median line and red towards the margins; and a faint blush was observed over the front of the chest, with a few. scattered papilla. Castor-oil and a warm bath were ordered; and the former acted freely in a short time. At 3 P.M., immediately after the bath, he had a yiolent attack of convulsions which lasted nearly half an hour; and, during that time, he became, according to his mother's account, quite black, foamed at the mouth, and was momentarily expected to die. $\Lambda$ fter the attack sub. sided, he continued quite delirious and more or less convulsed until 1 A.M. on January 7 th, when he asked a few questions rationally, and had a good voluntary evacuation from the bowels and bladder; the faces being very dark and offensive. At 6 A.M., he again became delirious. At II A.M., he was seen again by me, another surgeon having been in attendance in the meantime, when the delirium was extreme; the tongue, dry and brown, was protruded to its utmost and rolled from side to side the eyeballs were deeply suffused, the straight arteries being more especially prominent; the pupils were contracted to the finest point ; there was no squinting. The skin was hot and dry, but there was no appearance of eruption over any part, nor swelling of the throat. The pulse was very rapid, and felt with difficulty. Such continued to be his condition until 7 P.M., when death occurred ; excepting that the mother remarked that he became gradually cold from the feet upwards (in her own words, "died upwards"); and inmediately after death the body beme rapidly livid in the same direction.

CASE II. - A sister, aged 6 years and 6 months, with the same previous history as Case I, at 3 P.M. on January 8th, complained of headache and sickness and vomited freely. A dose of castor-oil was at once given, and acted well. Shortly after the vomiting, she became delirious, but not convulsed; and at II P.M., when I first saw her, the delirium was very marked; the whole body being ettremely hot, and the head especially so. The eyeballs were deeply suffused, as in the last case, with the same extent of contraction of the pupils. The pulse was very quick and small. There was no trace of eraption over the body. A warm bath, mustard to the calves, evaporating lotion to the head (this being shaved), and a purgative of grey powder and rhubarb, were ordered; and also a free supply of beef-tea and wine at frequent intervals in small quantities. During the night, the bowels acted three times, the freces being black and most offensive; and urine was passed, of high colour, but in good quantity. The delirium continued throughout the greater part of Jan. gth; but towards evening she became a little conscious, asked a few questions, and complained of great thirst and soreness of the throat. The tongue was then very red and dry; the eyes were a little less suffused; and the pupils not so markedly contracted. The pulse was as before. The head was decidedly cooler. She was partially delirious during the night, but took wine and beef-tea freely. The bowels were relieved twice.

January roth. This morning, for the first time, a well marked erup. tion broke out over the chest and abdomen. Delirium, however, was still present, with never ceasing restlessness. The skin was less hot; the pulse quieter, though very weak. She had taken large quantities of wine and beeftea, and had'had frce evacuation of freces and urine; the former not amounting, however, to diarrhœa. She was less restless during the night; and, on the morning of Jan. 1oth, the eruption was so fully developed, with dimimution of fever; that great hopes were entertained of her recovery. As the day advanced, however, she became gradually unconscious; the pupils dilated largely; and she died at II P.M.; the under surface of the body having previously become livid; the mother, remarking that she became cold first at the chest and lastly in the feet, said that she died downwards. The whole body became speedily livid.

It is greatly to be regretted that the parents would not consent to post morlem examinations.

The family consisted, excluding those who died, of parents and two children-one a girl of 18 years, and the other a boy of 18 months. The mother, on the evening of Jan. 5th, had a miscarriage of a two months' fotus; and, on the morning of the 8th, the father was atiacked with violent romiting, but nothing more. These four continue well; the baby's escape being probably attributable to the fact of his not having as yet been weaned. The rooms they occupy are lange and commodious. There is nothing wrong to be detected in the sanitary arrange. ments in or near them; nor are there any other cases of scarlatina in this station. The children rarely left the Tower, nor had they mixed with others residing outside it.

\section{A CASE WHERE OVARIOTOMY WAS UNSUCCESS. FULLY ATTEMPTED.*}

By THOMAS SMITH, EsQ., F.R.C.S., Assistant-Surgeon to St. Bartholomew's Hospital, London.

Tire subject of this account was a widow aged 39, who was admitted into St. Bartholomew's Hospital under my care, June 4 th, 1867. She was healthy but of spare frame. Eight years ago she had her last child; and immediately after her confinement she noticed a small firm swelling just above the left groin. This had gradually increased in size without causing pain until a year ago, since which time she had suffered at times severely. The catamenia had been regular until six weeks before admission; during the last few weeks she had lost blood frequently per vaginam. The swelling at the date of admission was increasing quickly in size, and she was scarcely able to perform her household duties.

On June $4^{\text {th }}$, 1867, the abdomen was symmetrically distended by a cyst. Fluctuation was very perceptible over the whole of its surface, which was dull to percussion; the only resonant parts of the abdomen being the flanks, the epigastrium, and the hypochondria. The abdominal walls apparently moved over the tumour, and were inadherent. When she raised herself from the recumbent position, the region of the recti muscles became very prominent, and the flanks compressed. There were in the abdominal walls one or two hard knots, which seemed to be unconnected with the tumour. The uterus was pushed very low down in the pelvis; its fundus was plainly to be felt with the finger. It could be moved from side to side pretty freely, but in other directions its movement was very restricted.

From the history of the case, and from the physical examination of the patient, little doubt existed in the minds of those of my colleagues who examined the woman, that she was suffering from an ovarian cyst, which was probably unilocular and perhaps inadherent. In accordance with this view, on July IIth, the operation of ovariotomy was undertaken. An incision about three inches in length was made in the linea alba. On dissecting through the abdominal wall, no smooth cyst-surface was reached as in ordinary ovarian disease, but a granular and ad. herent membrane distended with fluid. This was opened with a minute puncture; and, as fluid resembling that found in ovarian disease escaped, the separation of the cyst from the abdominal wall was attempted. This separation had been accomplished to some extent, when suddenly the cyst-wall gave way at the point of puncture, and an hydatid cyst escaped. The nature of the disease being now evident, the opening was enlarged, and an immense quantity of hydatids were discharged. They were of all sizes, from the size of a marble to that of a cocoa-nut. In all, eight pints of fluids escaped, and seven pints of hydatid cysts. The cysts were apparently living and in full vigour. The parent-cyst extencled far down into the pelvis, large numbers of hydatids being fished up from that cavity, and many more being forced out by pressure upwards made by the forefinger from the vagina. The cavity having been emptied as far as practicable, the cyst-walls were drawn out to some extent, and attached by silver sutures to the margins of the ex. ternal wound. A poultice was then applied.

The subsequent progress of the case was thoroughly satisfactory. The cyst was syringed twice daily with a weak solution of iodine (two drachms of the compound tincture to a pint of water). Oceasionally collapsed hydatids would escape after syringing. At no time was there any disagreeable odour from the wound. The fluid that $\infty$ caped was tinged apparently by bile, and gave with nitric acid the ordinary reaction of that fluid.

On September roth, the patient left the hospital in good health, with the wound soundly healed. Owing to the adhesion of the cyst-wall to the edges of the wound in the abdominal walls, the linea alba, though covered over with sound skin, remains ununited in its tendinous part; the patient is, therefore, obliged to wcar an abdominal belt to prevent protusion of the intestines.

REMARKS. - This case may serve to illustrate the uncertainty of the - Read at the meeting of the Shropshire Scientific Branch, Nov. 1867 . 
diagnosis of abdominal tumours. Though the operation of ovariotomy has been undertaken for many and various abdominal swellings, so far as I am aware, this is the first instance of hydatid cyst being mistaken for ovarian disease; nor does any justifiable means of investigation suggest itself to me whereby the error could have been avoided.

The staining of some of the cysts and of the fluid that escaped after the operation with bile negatives the supposition that the parent cyst originated in the pelvis, a supposition which the history of the case and such information as could be gained at the time of the operation would otherwise confirm. Though the cyst must have been of hepatic origin, yet its connections, so far as it could be ascertained, before, during, and after the operation, were chiefly among the lower part of the abdominal and pelvic regions. Nor is this peculiarity unique, namely, that an hydatid cyst, taking origin in the liver, should present in the pelvis. In the Medical Times and Gazctte of August 1864 is a case related by Dr. Sadler, where Cæsarean section was undertaken at the full period of gestation, on account of, as was supposed, a bony growth from the sacrum, which obstructed the lower outlet of the pelvis. This tumour, which was of bony hardness, proved at the post mortem examination to be a hydatid cyst, taking origin in the liver.

\section{REPORTS}

or

MEDICAL AND SURGICAL PRACTICE IN THE HOSPITALS OF GREAT BRITAIN.

\section{ST. BARTHOLOMEW'S HOSPITAL.}

ACUTE DISEASE OF THE RIGHT KNEE-JOINT, ENDING IN SUPPURATION, CAUSED BY A FALL ON THE KNEE.

(Under the care of Mr. SAVORY.)

G. L., aged 12, was admitted on September 2nd, I867, with the history that on Saturday, August 3ist, he was walking through a shed, slipped on some grease, and fell to the ground, striking the right knee. He did not complain of much pain at the time of the accident, and was not prevented from running about until the following day, when he suffered considerable pain, and the joint swelled much.

When admitted, two days afterwards, the joint was considerably swollen, red, hot, and exquisitely painful; the swelling taking the shape of the synovial membrane. The femur was not painful on pressure above the joint. He was ordered to have ten leeches to the joint, and a purge.

On the following day the pain was somewhat relieved, and the bowels acted freely. His tongue was furred and white; he had no appetite; there was general pyrexia. Pulse I20. The joint was ordered to be poulticed and placed on a pillow.

He had a very bad night; and next morning (Sept. 4th) the joint was more swollen and painful; but still there was no pain on pressure over the femur. The tongue was very much furred. Pulse 125; he had no appetite; his bowels were open.

September $5^{\text {th. }}$ He had a very restless night, and the joint was more painful and much more swollen than ever; and there was distinct fluctuation over the patella. Mr. J. F. Williams, the House-Surgeon, who kindly gave us the notes of the case, made an incision and let out about three ounces of pus, which considerably relieved the pain. The tongue was furred, but moist. His bowels were open; pulse 128; skin hot and perspiring; face anxious.

A much better night followed this relief to the knee. He had not so much pain in the knee. Pulse 125. The patella could be felt distinctly riding over the condyles of the femur. His general condition was not improved. Mr. Savory introduced a grooved needle into the joint from the outer side, when some purulent fluid escaped; and, on enlarging the opening to the extent of two inches, matter gushed out freely. The leg was immoveably fixed in an ordinary McIntyre splint. Three hours after the operation, the patient expressed himself as much relieved. Pulse r 20.

He again had a good night; and on the morning of the 7 th he was free from pain, and there was little discharge from the joint. The face was somewhat flushed; expression better. There was a slight white fur on the tongue, which was, however, moist. The bowels were not open this morning, but twice last evening; skin warm but moist. Pulse I20.

On September 8th, he slept very well; the expression of his face was better. Tungue cleaner and moister; bowels open; pulse 124, of good power; appetite pretty good.

On the gth, he looked quite cheerful, and had had two very good nights. He had no pain. Tongue clean; bowels open; appetite good.
The skin over the knee-joint was wrinkled; the discharge was scanty. His skin was moist and cool.

On the Ioth, he had slept very well. Tongue quite clean and moist; bowels not open; appetite improving; skin natural; pulse 120, regular, of good power; expression of face good. The wound was discharging more freely; he had no pain. The swelling of the thigh was much diminished. His general condition was much improved since the joint was opened.

On the I Ith, he had not slept so well during the night. Tongue somewhat white, but moist; skin cool; pulse quicker than it was (140), but regular; bowels open; appetite good. He was ordered meat diet. The wound looked healthy; the discharge was more profuse. There was no tension about the joint.

During the next three days he progressed favourably. He had some pain in the knee during the night of the $13^{\text {th }}$, but none next morning. There was healthy pus discharging. Pulse 145-150, of good power. He was ordered to have twenty minims of liquor cinchonæ twice daily. He continued to sleep well.

October 3 rd. He continued to do well up to this date; the discharge gradually ceased some days previously, and the wound quite healed up.

On the 3oth, his condition had much improved in every respect. A few days before a small piece of the patella exfoliated. Firm pressure on the patella now caused him no pain.

Shortly afterwards, the leg was put up in a gutta-percha back-splint. On Nov. 25th, he was noted to have no pain; motion-flexion and extension-were free and smooth.

\section{GUY'S HOSPITAL.}

INTESTINAL OBSTRUCTION FROM VOLVULUS OF THE CACUM AND ASCENDING COLON: PERITONITIS: DEATH.

(Under the care of Dr. HaBershon.)

WE are indebted for the following report to Dr. J. Thompson Dickson.

T. P., aged 44, a stable-helper, was admitted into the clinical ward of Guy's Hospital on December 11th, 1867. He was in a dreamy condition when admitted, so that his own account was not very reliable. He said he had always enjoyed good health till within a month of his admission, when he was troubled with constipation, the distress of which was greatly aggravated during the last fortnight. He had taken purgative pills, and enemata had been administered, which had kept the bowels freely open till Saturday, December 7 th. His wife, how: ever, stated that his bowels had not acted rightly for a long time, and had not been moved for nine or ten days before admission, but that they had been freely opened at the onset of the attack.

On admission, he was pale and very ill; his abdomen was tympanitic, immensely distended, of pyriform shape, the greatest diameter being immediately below the ribs; and its walls were raised into prominent elevations by transverse folds of distended intestine beneath. His pulse was I12, small and thready, and his respirations were $3^{2}$. His heart and lungs gave no abnormal sounds. The rectum contained fres, but no obstruction could be felt. He was almost free from pain. He constantly hawked up mucus tinged with bile, though not in large quantity. He had passed a normal quantity of urine. During the night he was delirious, and on the following day he was more drowsy, and his respiration was nuch embarrassed by reason of the encrmous abdominal distension. At II A.M. he vomited a quantity of yellowish and also black brown material, apparently the contents of the small intestine. At 12.0 P.M. a small trocar and cannula were introduced into what appeared the prominent transverse colon, and a large amount of gas escaped, with a small quantity of a coagulable fluid containing globules with irregular edges and a single granular nucleus; this relieved him much. When seen by Dr. Habershon at I P.M. his left hypochondriac region was dull posteriorly, while the right was tympanitic. He complained of a low diffused pain at the lower part of the abdomen, but there was no tenderness anywhere. He was ordered a grain of powdered opium and a quarter of a grain of extract of belladonna every four hours. At 8.30 P.M. violent vomiting returned, and at I0.30 P.M. he died.

Autorsy - I 4 hours after death. There was abundant recent lymph on the surfaces of both pleuræ. No fluid, however, was found in the cavity of the chest. The small intestine was dilated to a diameter of two inches, and lay in transverse folds in the front of the abdomen, in appearance not unlike large intestine. The cæcum, immensely dilated and somewhat thickened, occupied the left hypochondrium, and very much resembled the stomach. It contained an enormous quantity of frecal matter, but the ileo-cæcal valve was unobstructed; but, a few inches above the cæcum, the ascending colon was small and contracted, with a very 